\section{Professional writers can help to improve clarity of medical writing}

The editorial by Roger Collier calls for the clear presentation of study findings, to ensure that results that have been carefully gathered are appropriately communicated. ${ }^{1}$ The Global Alliance for Publication Professionals agrees with these sentiments, and states, "Most of the responsibility for improving writing in academic medicine, however, falls upon the physicians and scientists who produce it."However, it has been shown that the major barrier to publishing research is lack of time, ${ }^{2,3}$ which may well lead to poorly written manuscripts, as well as nondisclosure of results. The issue of waste in biomedical research has been tackled before, ${ }^{4}$ and the Global Alliance for Publication Professionals has previously highlighted the role that professional medical writers could play in resolving the burden of time constraints and lack of training faced by researchers (see PubMed Commons comments ${ }^{4}$ ).

We would like to emphasize the role of professional medical writers in helping authors deliver high-quality, accurate and timely manuscripts in an ethical and transparent manner. Such medical writers are highly qualified individuals, combining scientific rigour, in-depth knowledge of publication guidelines and aptitude for effective communication..$^{5-7}$ Professional writing services have a recognized impact on publication success, ${ }^{8-13}$ and although such professional assistance does have budgetary implications, as previously suggested, provision could be included in research ${ }^{4}$ or departmental budgets. ${ }^{3,14}$ Indeed, there may be cost savings associ- ated with the lower time requirement for authors preparing a high-quality, readable, concise and accurate manuscript that adheres to a journal's instructions to authors and applicable best practices.

\section{Julia A. Donnelly BPharm PhD}

Publication Professional, Julia Donnelly

Solutions Ltd., Ashbourne, UK

\section{Jackie Marchington PhD}

Director of Global Operations and General

Manager, Caudex, Oxford, UK

Art Gertel PhD

President and Principal Consultant, MedSciCom, LLC, Lebanon, NJ

\section{Serina Stretton PhD}

Scientific Solutions Lead, ProScribe Envision Pharma Group, Sydney,

Australia

Cite as: CMAJ 2018 March 5;190:E268. doi: $10.1503 / \mathrm{cmaj} .68670$

\section{References}

1. Collier R. A call for clarity and quality in medical writing. CMAJ 2017;189:E1407.

2. Scherer RW, Ugarte-Gil C, Schmucker C, et al. Authors report lack of time as main reason for unpublished research presented at biomedical conferences: a systematic review. J Clin Epidemiol 2015;68:803-10.

3. Duracinsky M, Lalanne C, Rous L, et al. Barriers to publishing in biomedical journals perceived by a sample of French researchers: results of the DIAzePAM study. BMC Med Res Methodol 2017;17:96

4. Glasziou P, Altman DG, Bossuyt $\mathrm{P}$, et al. Reducing waste from incomplete or unusable reports of biomedical research. Lancet 2014;383:267-76.

5. Winchester C. AMWA-EMWA-ISMPP joint position statement on the role of professional medical writers; 2017. Available: http://journal.emwa.org/ writing-better/amwa-emwa-ismpp-joint-position -statement-on-the-role-of-professional-medical -writers/ (accessed 2017 Nov. 27).

6. Wager E, Woolley K, Adshead V, et al. Awareness and enforcement of guidelines for publishing industry-sponsored medical research among publication professionals: the Global Publication Survey. BMJ Open 2014;4:e004780.

7. Battisti WP, Wager E, Baltzer L, et al. Good publication practice for communicating companysponsored medical research: GPP3. Ann Intern Med 2015;163:461-4.

8. Gattrell WT, Hopewell S, Young K, et al. Professional medical writing support and the quality of randomised controlled trial reporting: a crosssectional study. BMJ Open 2016;6:e010329.

9. Hamilton CW, Gertel A, Jacobs A, et al. Mythbusting medical writing: goodbye ghosts, hello help. Account Res 2016;23:178-94.

10. Woolley KL, Lew RA, Stretton S, et al. Lack of involvement of medical writers and the pharmaceutical industry in publications retracted for misconduct: a systematic, controlled, retrospective study. Curr Med Res Opin 2011; 27:1175-82.

11. Marchington JM, Burd GP. Author attitudes to professional medical writing support. Curr Med Res Opin 2014;30:2103-8.

12. Jacobs A. Adherence to the CONSORT guideline in papers written by professional medical writers. The Write Stuff 2010;19:196-200.

13. Mills I, Sheard C, Hays M, et al. Professional medical writing support and the reporting quality of randomized controlled trial abstracts among highimpact general medical journals. F1000Res 2017; 6:1489.

14. Manring MM, Panzo JA, Mayerson JL. A framework for improving resident research participation and scholarly output. J Surg Educ 2014;71:8-13.

Competing interests: The Global Alliance for Publication Professionals (www.gappteam.org) is a group of independent individuals who volunteer their time and receive no funding (other than website hosting fees from the International Society for Medical Publication Professionals). All Global Alliance for Publication Professionals members have held or hold leadership roles at associations representing professional medical writers (e.g., the American Medical Writers Association, the European Medical Writers Association, Driving Insights into Action, the International Society for Medical Publication Professionals, the Association of Regulatory and Clinical Scientists), but do not speak on behalf of those organizations. Global Alliance for Publication Professionals members have or do provide professional medical writing services to not-for-profit and for-profit clients. 